\title{
ZnS Nanocrystals as an Additive for Gamma-Irradiated Poly (Vinyl Chloride)
}

\author{
Roberta Cristina da Silva ${ }^{a}$ Lindomar Avelino da Silva ${ }^{a}$ Patricia Lopes Barros de Araújo ${ }^{\text {, Elmo }}$

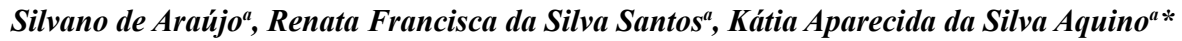 \\ ${ }^{a}$ Laboratório de Polímeros e Nanoestruturas, Departamento de Energia Nuclear, Universidade Federal \\ de Pernambuco, Av. Prof. Luiz Freire, 1000, 50740-545, Recife, PE, Brazil
}

Received: December 11, 2016; Revised: December 07, 2017; Accepted: December 08, 2017

\begin{abstract}
Zinc sulfide $(\mathrm{ZnS})$ was synthesized by sonochemical method and nanoparticles with crystallite size around $2 \mathrm{~nm}$ were obtained. PVC containing $\mathrm{ZnS}$ nanoparticles at concentrations of 0.10; 0.30; $0.50 ; 0.7$ and $1.00 \mathrm{wt} \%$ were gamma irradiated $\left({ }^{60} \mathrm{Co}\right)$ at room temperature in air. No appreciable decrease in PVC Viscosity-Average Molar Mass $\left(\mathrm{M}_{\mathrm{v}}\right)$ was observed for samples containing $0.7 \mathrm{wt} \%$ of $\mathrm{ZnS}$ nanocrystals. It was demonstrated that the addition of $\mathrm{ZnS}$ nanocrystals imparted molecular protection to the polymer matrix while improving flexibility, by decreasing the Young Modulus of PVC films. These results suggest the use of sonochemically synthesized $\mathrm{ZnS}$ nanocrystals as a new additive for radiation-grade PVC materials.
\end{abstract}

Keywords: Zinc sulfide nanocrystals, sonochemical synthesis, radiolytic degradation, stabilization.

\section{Introduction}

Polymer composites might present improved physical properties when compared to their polymer matrices counterparts. Thus, new combination of materials can be manufactured to meet specific requirements, which are difficult to fulfill by using a single component ${ }^{1}$.

Poly (vinyl chloride) (PVC) is a suitable polymer matrix for composites, because of its low cost, good chemical stability, and biocompatibility ${ }^{2}$. Furthermore, PVC is compatible with a wide range of additives and undergoes remarkable changes in its properties due to additivation ${ }^{3}$.

Zinc sulfide $(\mathrm{ZnS})$, along with many other inorganic sulfides, exhibits a broad range of useful properties. This sulfide presents good chemical stability and physical strength, being first used as a semiconductor ${ }^{4,5}$.

Kolahi and co-workers ${ }^{6}$ fabricated $\mathrm{ZnS}$ nanocrystals embedded in polyvinyl alcohol (PVA) matrix by wet chemical method, and observed quantum confinement effect in these nanocomposites. Ogata and collaborators ${ }^{7}$ prepared polymer/ $\mathrm{ZnS}$ nanoparticle composites by matrix-mediated synthesis and obtained homogeneously dispersed nanoparticles in the polymer, which may be useful for quantum dots and optical devices. Osuntokun and Ajibade ${ }^{8}$ reported the synthesis and structural studies of $\mathrm{ZnS}$ and $\mathrm{CdS}$ nanoparticles in polyvinylpyrrolidone, PVA, and poly(methyl methacrylate) matrices. They prepared metal sulfides/polymer nanocomposites by solution casting method, with good results. Tiwari and Dhoble ${ }^{9}$ reported surface passivation of $\mathrm{ZnS}$ nanoparticles in various polymer ligands/matrices.
Ultrasound irradiation is an effective method for inorganic nanoparticles synthesis, with advantages such as accelerating chemical reactions, enhancing mass transfer, shortening reaction cycles, improving reaction yield, altering reaction pathways, increasing surface area between the reactants, and accelerating dissolution, among others ${ }^{10}$.

The primary sonochemistry mechanism is based on acoustic cavitation, which is the formation, growth and collapse of bubbles in a liquid. Violent collapse of bubbles in less than a microsecond produces extreme heat, forming short-lived hot spots, and high pressure. These extreme transient conditions allow synthesis on the benchtop, at room-temperature conditions, in media that would otherwise require high temperatures, high pressures, or long reaction times $^{11,12}$. Zinc sulfide sonochemical synthesis is a suitable preparation method, which allows fast and simple obtention of morphologically pure products ${ }^{13-18}$, circumventing tedious and laborious methods already described in the literature ${ }^{19,20}$.

PVC has applications that range from rigid pipes to electron-beam or gamma irradiation sterilizable medical devices.. However, when submitted to gamma irradiation, PVC molecular structure might degrade as a result of main chain scissions and crosslinking effects ${ }^{21,22}$.

In this paper, we present sonochemically synthesized $\mathrm{ZnS}$ nanocrystals as a new additive for radiation-grade PVC. Our findings suggest that $\mathrm{ZnS}$ nanocrystals are suitable radiostabilizers for gamma-irradiated PVC, while enables lower matrix rigidity. Our work contributes to the development of inorganic nanomaterials as active fillers for commodity polymers. 


\section{Materials and Methods}

\subsection{Synthesis and characterization of $\mathrm{ZnS}$ nanocrystals}

All reagents used were of analytical grade. Zinc acetate hydrate $\left(\mathrm{C}_{4} \mathrm{H}_{6} \mathrm{O}_{4} \mathrm{Zn} . \mathrm{H}_{2} \mathrm{O}\right)$ (VETEC ${ }^{\circledR}$, Brazil), thioacetamide $\left(\mathrm{CH}_{3} \mathrm{CSNH}_{2}\right)$ (Sigma Aldrich), absolute ethanol (FMAIA ${ }^{\circledR}$, Brazil) and tetrahydrofuran (THF) (VETEC $®$, Brazil) were used without further purification. Methyl-ethyl-ketone (MEK) (DINAMICA ${ }^{\circledR}$, Brazil) was dried with $\mathrm{Na}_{2} \mathrm{SO}_{4}$ and purified by distillation prior to use.

A typical reaction procedure was done with $1.317 \mathrm{~g}$ of $\mathrm{C}_{4} \mathrm{H}_{6} \mathrm{O}_{4} \mathrm{Zn} . \mathrm{H}_{2} \mathrm{O}$ and $1.35 \mathrm{~g}$ of thioacetamide dissolved in 100 $\mathrm{ml}$ of absolute ethanol in a $250 \mathrm{ml}$ beaker. Then, ultrasonic irradiation was performed for 30 minutes with a high-intensity ultrasonic probe (Sonic, $20 \mathrm{kHz}, 500 \mathrm{~W}$ ) directly immersed in the reaction medium, under $100 \%$ ultrasound intensity, to form the precipitate. After the reaction, the obtained $\mathrm{ZnS}$ precipitate was centrifuged (Quimis centrifuge Q222TM, Relative Centrifugal Force (RCF) 2,555xg), washed successively with absolute ethanol, distilled water, and acetone, and then placed in a desiccator at room temperature until complete solvents evaporation. The final product was inspected by Scanning Electron Microscopy (SEM, Quanta 200 FEG) in gold-coated samples at a magnification of $6000 \mathrm{x}$.

$\mathrm{X}$-ray powder diffraction (XRD) analysis of the product was carried out with a Siemens D5000 Diffractometer, equipped with graphite monochromator $(\mathrm{CuK} \alpha$ radiation $\lambda=$ $1.5418 \AA \hat{\text { }}$ ) using a scanning rate of $0.02 \mathrm{deg} / \mathrm{s}$ in the $2 \theta$ range from $5^{\circ}$ to $80^{\circ}$. Crystallite size was calculated according to the Debye-Scherrer formula using Equation $1^{19}$ :

$$
L=\frac{0.9 \lambda}{B \cos \theta}
$$

where $\mathrm{L}$ is the coherence length, $\mathrm{B}$ is the full width at half maximum of the diffraction peak unit, $\lambda$ is the wavelength of the X-ray radiation, and $\theta$ is the Bragg angle of the diffraction peak.

Energy Dispersive Spectroscopy (EDS) experiments and Transmission Electron Microscopy (TEM) images were obtained using a G 200 microscope (FEI Tecnai 20, USA) operating at $200 \mathrm{kV}$, in bright field mode. All samples were prepared by dripping a small amount of a diluted ethanol suspension atop a 400 mesh carbon-coated copper grid and allowing the solvent to evaporate.

\subsection{Preparation of PVC films}

Additive-free PVC (BRASKEM, Brazil) was used as supplied. PVC and PVC with $\mathrm{ZnS}(\mathrm{PVC} / \mathrm{ZnS})$ films were prepared by solvent-casting from MEK solvent by slow evaporation in air at room temperature $\left(\approx 27^{\circ} \mathrm{C}\right)$. Concentrations of $\mathrm{ZnS}$ nanocrystals used in this study were $0.10 ; 0.30 ; 0.50 ; 0.7$ and $1.00 \mathrm{wt} \%$. Films were characterized by Scanning Electron Microscopy (SEM, Quanta 200FEG) in gold-coated samples.

\subsection{Viscosity measurements}

Cinematic viscosity of PVC and PVC/ZnS THF solutions were carried using an Anton Paar SVM 3000 Stabinger Viscometer. Viscosity results were obtained from the Equations showed in Table 1. Viscosity Average Molar Mass $\left(\mathrm{M}_{\mathrm{v}}\right)$ was calculated from the corresponding $[\eta]$ values through Mark-Houwink Equation ${ }^{23}$ (Equation 2).

$$
[\eta]=K M_{v}^{a}
$$

where $K$ and $a$ are $1.5 \times 10^{-4} \mathrm{dL} / \mathrm{g}$ and 0.766 , respectively for the THF-PVC system at $25^{\circ} \mathrm{C}^{24}$.

The action of $\mathrm{ZnS}$ nanocrystals on PVC matrix was assessed by comparison of the Degradation Index (DI) for irradiated samples using Equation 3.

$$
D I=\left(\frac{M_{V 0}}{M_{V}}\right)-1
$$

where $M_{v 0}$ and $M_{v}$ are the Viscosity Average Molar Mass before and after gamma irradiation, respectively. DI is obtained from viscosity analysis and reflects the number of main chain scissions per original molecule after irradiation ${ }^{25}$.

\subsection{Irradiation of samples}

$\mathrm{PVC}$ and $\mathrm{PVC} / \mathrm{ZnS}$ films were exposed to gamma radiation from a non-attenuated ${ }^{60} \mathrm{Co}$ source (Gammacell GC220 Excel irradiator - MDS Nordion, Canada), at $25 \mathrm{kGy}$ dose in air, dose rate of $2.66 \mathrm{kGy} / \mathrm{h}$, at room temperature $\left(\approx 27^{\circ} \mathrm{C}\right)$.

\subsection{Free radical scavenging action of $\mathrm{ZnS}$ nanocrystals}

The free radical scavenging action assessment was grounded on DPPH (2,2-diphenyl-1-(2,4,6-trinitrophenyl)-hydrazyl) radical strong visible light absorption, characterized by an intense violet coloration due to the presence of unpaired electrons $^{27}$. In the presence of radical scavengers, DPPH solution color fades, leading to a stoichiometric discoloration in relation to the number of reduced DPPH radicals. In brief, $2.4 \mathrm{mg}$ of DPPH were dissolved in $10 \mathrm{~mL}$ of the absolute ethanol and $1.2 \mathrm{mg}$ of $\mathrm{ZnS}$ nanocrystals (equivalent to a concentration of $0.7 \mathrm{wt} \%$ in PVC matrix) were mixed with the DPPH solution under vigorous stirring at room temperature $\left(\approx 27^{\circ} \mathrm{C}\right)$ for 30 minutes. Free radical scavenging action of $\mathrm{ZnS}$ was evaluated through the decrease in DPPH solution visible absorption at $515 \mathrm{~nm}$, using BHT (2,6-bis(1,1dimethylethyl)-4-methylphenol) as a positive control.

\subsection{Mechanical properties}

Tensile properties of the PVC and $\mathrm{PVC} / \mathrm{ZnS}$ were determined according to ASTM D-882-12 ${ }^{28}$ using an Instron machine EMIC, DL-500 N. Results were expressed as the mean value of four samples. The tests took place at room 
Table 1. Equations used for viscosity measurements.

\begin{tabular}{|c|c|c|c|}
\hline Viscosity measurement & Equation & Description & Reference \\
\hline Relative viscosity $\left(\eta_{\text {rel }}\right)$ & $\eta_{\mathrm{rel}} \approx v / v_{0}$ & $\begin{array}{c}v \text { and } v_{0} \text { are the cinematic viscosities on the polymer } \\
\text { solution and the solvent, respectively }\end{array}$ & 23 \\
\hline Specific viscosity $\left(\eta_{\mathrm{sp}}\right)$ & $\eta_{\mathrm{sp}}=\eta_{\mathrm{rel}}-1$ & - & 23 \\
\hline reduced viscosity $\left(\eta_{\text {red }}\right)$ & $\eta_{\mathrm{red}}=\eta_{\mathrm{sp}} / \mathrm{C}$ & $\mathrm{C}$ is solution concentration $(0.6 \mathrm{~g} / \mathrm{dL})$ & 23 \\
\hline Intrinsic viscosity [ ] & $\frac{1}{C} \sqrt{2\left(\eta_{s p}-\ln \eta_{r e l}\right)}$ & - & 26 \\
\hline
\end{tabular}

temperature. Assays were performed under the following conditions: load cell of $500 \mathrm{~N}$, crosshead speed of $2 \mathrm{~mm} /$ min, and sample dimension of $2.5 \times 7.5 \times 0.12 \mathrm{~cm}$.

\subsection{FTIR characterization}

Fourier Transform Infrared (FTIR) spectra were obtained using a Jasco 4600 FTIR Spectrometer (Tokyo, Japan), equipped with an attenuated total reflection accessory (ATR ProOne, ZnSe crystal), operating at a $4 \mathrm{~cm}^{-1}$ resolution , ranging from 400 to $4000 \mathrm{~cm}^{-1}$ with 75 scans/spectrum.

\subsection{Principal Component Analysis (PCA) of FTIR spectra}

PCA was performed using PVC and PVC/ZnS FTIR data in the $2000 \mathrm{~cm}^{-1}-500 \mathrm{~cm}^{-1}$ wavelength range. FTIR spectra were exported in the JCAMP-DX format and treated with The Unscrumbler ${ }^{(\mathrm{r})} 9.7$ software (CAMO Software AS, Norway). Spectra were made in quintuplicate. Raw data were normalized and modelled to determine variable scores and assess which components are able to explain major variabilities in the spectroscopic data matrix.

\section{Results and Discussion}

\subsection{ZnS nanocrystals characterization}

Fast and simple sonochemical method was used to obtain $\mathrm{ZnS}$ nanocrystals from $\mathrm{C}_{4} \mathrm{H}_{6} \mathrm{O}_{4} \mathrm{Zn} \cdot \mathrm{H}_{2} \mathrm{O}$ and thioacetamide, as evidenced by XRD analysis. X-ray diffractogram of sonochemically produced $\mathrm{ZnS}$ is shown in Figure 1 . The diffraction peaks at $2 \theta$ values of $29.44^{\circ}, 48.46^{\circ}$ and $56.69^{\circ}$ match well (111), (220), and (311) crystalline planes of cubic $\mathrm{ZnS}$, respectively. The significant broadening of the diffraction peaks may be attributed to small $\mathrm{ZnS}$ crystallite sizes. The crystal size estimated from the intense $2 \theta=29.44^{\circ}(111)$ XRD peak is about $2 \mathrm{~nm}$, according to the Debye-Scherrer equation (Equation 1). These results confirm the formation of $\mathrm{ZnS}$ with good crystallinity in cubic (sphalerite) phase and agree with literature results ${ }^{29}$.

$\mathrm{ZnS}$ nanoparticles morphology was analyzed by SEM experiments (Figure 2). It was observed that the $\mathrm{ZnS}$ crystals form spherical aggregates around $600 \mathrm{~nm}$. Nanoparticles agglomeration is expected as their high surface area make them thermodynamically unstable. Nanoparticle close contact reduces total exposed area, decreasing energy surface, therefore, stabilizing the particles ${ }^{30,31}$.

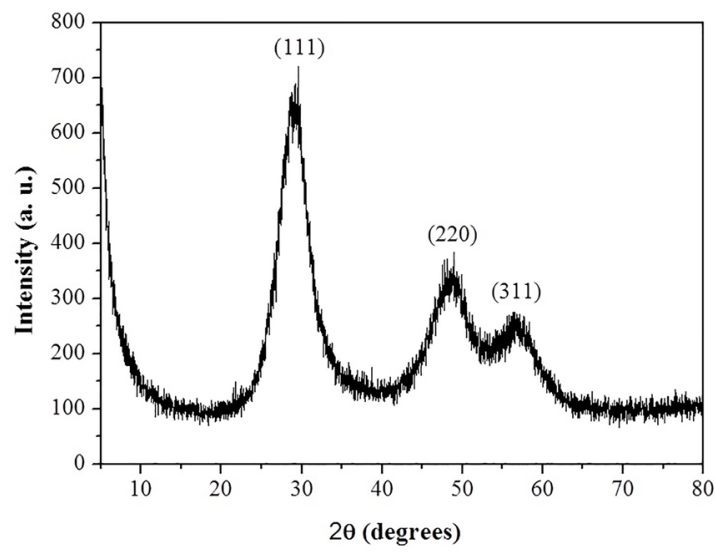

Figure 1. XRD pattern of $\mathrm{ZnS}$ nanoparticles.
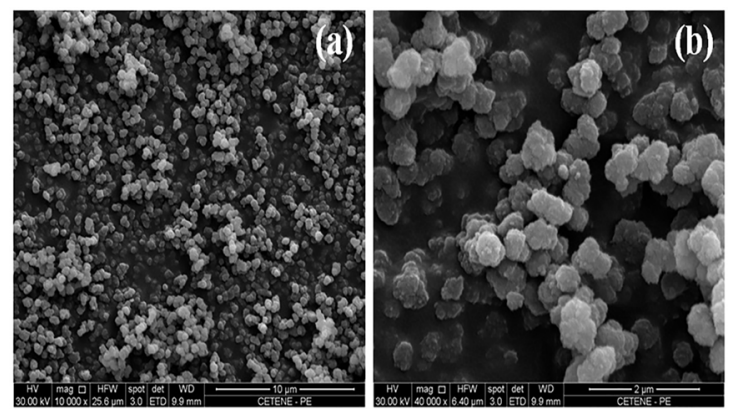

Figure 2. SEM micrographs for $\mathrm{ZnS}$ nanoparticles in a)10,000x and b) $40,000 x$.

TEM analysis evidenced $\mathrm{ZnS}$ crystals with diameters ranging from 2 to $3 \mathrm{~nm}$. (Figure 3a). Qualitative EDS analysis revealed $\mathrm{S}$ and $\mathrm{Zn}$ peaks, further confirming the samples identity, as shown in Figure $3 b$.

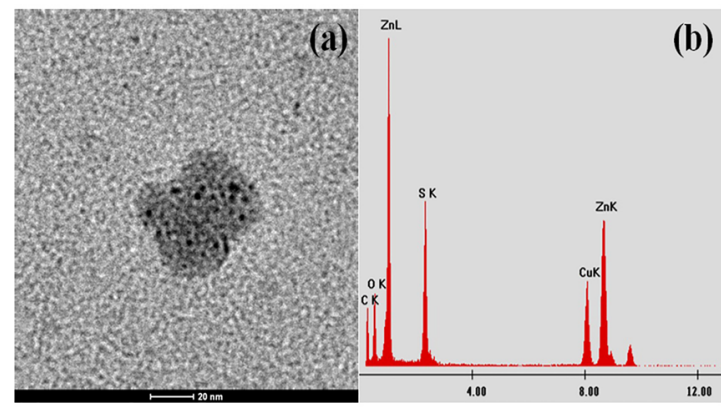

Figure 3. a)TEM micrograph and b) EDS result for $\mathrm{ZnS}$ nanoparticles. 


\subsection{Radiostabilizing action of $\mathrm{ZnS}$ nanocrystals in PVC matrix}

When PVC was exposed to gamma radiation at $25 \mathrm{kGy}$, its Mv decreased and DI value found was 0.094 as shown in Table 2. These results suggest the predominance of main chain scissions upon irradiation, in agreement with literature reports about gamma radiation effects on PVC matrix ${ }^{32-34}$. However, minor effect in Mv occurred in irradiated PVC/ $\mathrm{ZnS}$ films with increase of $\mathrm{ZnS}$ concentration up to $0.7 \mathrm{wt} \%$, with calculated DI $=0.024$. These results evidenced around $74 \%$ less scissions per original molecule of PVC, leading to an effective radiolytic stabilization of the polymer matrix owed to the presence of $\mathrm{ZnS}$ nanocrystals. In addition, a decrease in $\mathrm{ZnS}$ stabilizing action occurred when its concentration reached $1.00 \%$ wt. This is a rather common effect in polymer-additives systems as optimum additive concentration is overreached $\mathrm{d}^{13,14}$.

Table 2. Viscosity results for $\mathrm{PVC}$ and $\mathrm{PVC} / \mathrm{ZnS}$ at different concentrations.

\begin{tabular}{ccc}
\hline ZnS concentration (\% wt) & DI & Protection(\%) \\
\hline 0 & 0.094 & ---- \\
0.1 & 0.091 & 3.52 \\
0.3 & 0.086 & 8.69 \\
0.5 & 0.073 & 22.16 \\
0.7 & 0.024 & 74.56 \\
1.0 & 0.102 & Zero \\
\hline
\end{tabular}

To the best of our knowledge, no information about the use of $\mathrm{ZnS}$ nanocrystals in radiolytic stabilization of polymers has been published, so far. Consequently, many aspects of the radiostabilizing mechanism remain unclear. In this work, ZnS nanocrystals are suggested to play an important role in PVC radiostabilization. It is well known that gamma rays can break covalent bonds in PVC molecule to directly produce radicals, leading to further PVC degradation ${ }^{35,36}$. Nevertheless, our attempts to detect radical scavenging activities in $\mathrm{ZnS}$ nanocrystals using DPPH test were not successful. Intense violet coloration of DPPH solution (Figure 4a) showed no appreciable discoloration after $\mathrm{ZnS}$ nanocrystals addition in concentration equivalent to $0.7 \mathrm{wt} \%$ used in the PVC matrix. For comparison, BHT, the positive control, exhibited radical scavenging capacity by discoloring DPPH solution (Figure 4c).

Probably, $\mathrm{ZnS}$ acts as a quencher, deactivating excited states species formed during irradiation. Such activity was reported before in sulfur-containing substances, e.g. hydrogen sulfide, ethanothiol or diethylsulfide ${ }^{37}$, however further work is required to elucidate the processes involved in the stabilizing action of $\mathrm{ZnS}$ nanocrystals in PVC matrix.

\subsection{PVC/ZnS films characterization}

SEM images of $\mathrm{PVC} / \mathrm{ZnS}$ at studied concentrations showed similar behavior with homogeneous dispersion of nanoparticles in the polymer matrix. Figure 5 shows SEM images of PVC and PVC/ZnS film containing $0.7 \mathrm{wt} \%$ of $\mathrm{ZnS}$ presenting randomly distributed nanoparticle aggregates. The small $\mathrm{ZnS}$ size may induce aggregation of the nanoparticles to energetically stabilize $\mathrm{PVC} / \mathrm{ZnS}$ system, thus lowering the homogeneity of particle distribution. SEM images of irradiated nanocomposites presented similar features as nonirradiated nanocomposites and are not shown in this paper.

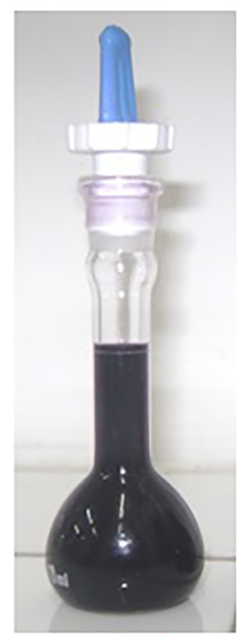

a)

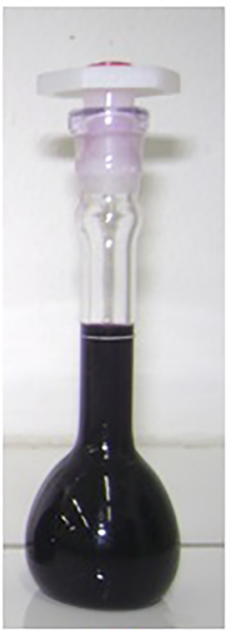

b)

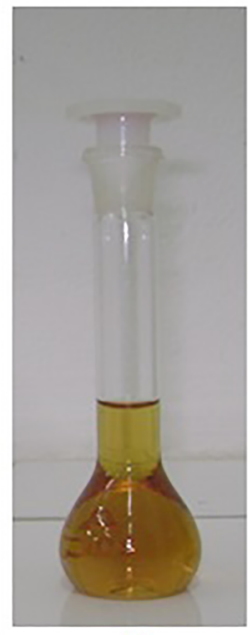

c)
Figure 4. DPPH radical results: a) DPPH solution, b) $\mathrm{DPPH}+\mathrm{ZnS}$ and c) $\mathrm{DPPH}+\mathrm{BHT}$.

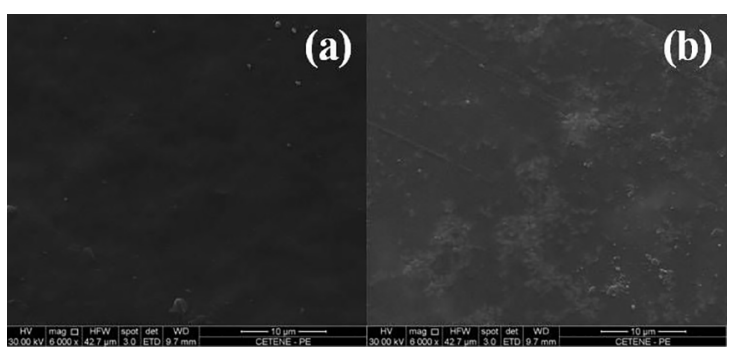

Figure 5. SEM micrographs of a) $\mathrm{PVC}$ film and b) $\mathrm{PVC} / \mathrm{ZnS}$ film $(0.7 \% w t)$

FTIR spectroscopy was used to detect and identify the presence of intermolecular interactions between PVC molecules and $\mathrm{ZnS}$. Figure 6 shows FTIR spectra of PVC and PVC/ $\mathrm{ZnS}(0.7 \mathrm{wt} \%)$ for non-irradiated and irradiated films in the $4000-500 \mathrm{~cm}^{-1}$ wavenumber region. $\mathrm{C}=\mathrm{O}$ stretching vibration in $1717 \mathrm{~cm}^{-1}$ is typical of ketone/aldehyde ${ }^{38}$, and may be attributed to residual MEK solvent used in the production of samples. Characteristic PVC vibrational modes can be 
classified in five types ${ }^{38,39}$ : a) C-Cl stretching $600-700 \mathrm{~cm}^{-1}$ range ; b) C-C stretching vibrations in the $900-1200 \mathrm{~cm}^{-1}$ range c) $\mathrm{CH}_{2}$ deformation in the $1300-1350 \mathrm{~cm}^{-1}$ range $\mathrm{d}$ ) C-H rocking 1240 - 1260 and trans- C-H wagging 950 - 960 $\mathrm{cm}^{-1}$ range. All spectra exhibited peaks within the expected range. However, shifts in $\mathrm{C}-\mathrm{Cl}$ stretching band were found in $\mathrm{PVC} / \mathrm{ZnS}$ spectra when compared to PVC data. PVC peak at $692 \mathrm{~cm}^{-1}$ is shifted to $681 \mathrm{~cm}^{-1}$ in $\mathrm{PVC} / \mathrm{ZnS}$ for non-irradiated samples. On the other hand, PVC peak at $692 \mathrm{~cm}^{-1}$ is shifted to $688 \mathrm{~cm}^{-1}$ in irradiated samples, but no significant shifts were found between irradiated $\mathrm{PVC} /$ $\mathrm{ZnS}$ samples. Such changes in $\mathrm{C}-\mathrm{Cl}$ stretching peaks suggest molecular interactions between PVC chlorine atoms and $\mathrm{ZnS}$, and might shed some light on the radiolysis protection mechanism, since the loss of chlorine radicals is the main initiation step for PVC radiolysis ${ }^{40}$.

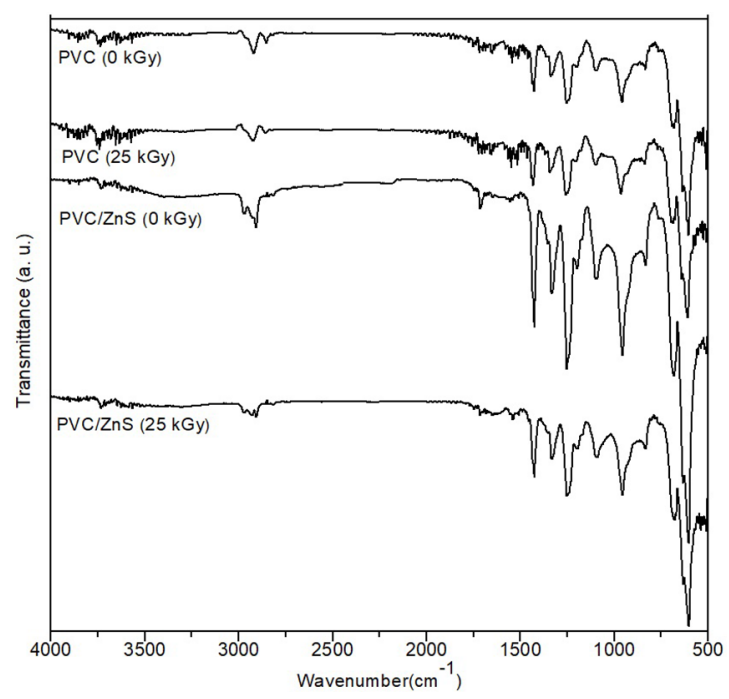

Figure 6. FT-IR spectra for PVC and PVC/ZnS $(0.7 \%$ wt) irradiated and unirradiated.

Further evidences on intermolecular interactions between PVC and ZnS nanocrystals could be assessed by PCA analysis of FTIR spectra. Figure 7 shows that PCA for PVC and $\mathrm{PVC} / \mathrm{ZnS}$ were separated into two distinct groups. This result means that there were differences between the systems and suggest specific PVC - ZnS interactions . The loading spectra showed more relevant changes for $\mathrm{C}-\mathrm{Cl}$ peak in the $\mathrm{PVC} / \mathrm{ZnS}$ sample. The percentages of variance explained by PC1 and PC2 were $98 \%$ and $1 \%$, respectively. PCA of PVC irradiated samples revealed a tendency of separation in two distinct vertical groups (Figure 8) . Loading data also suggest the most striking differences in the vibrations of the $\mathrm{C}-\mathrm{Cl}$ group with slight chemical shift, probably due to irradiation effects. However, for $\mathrm{PVC} / \mathrm{ZnS}$ samples it is possible to observe that, although there is a trend of vertical separation of groups, the samples data distribution are very close; which means that there are small differences in the vicinity of PVC
$\mathrm{C}-\mathrm{Cl}$ bonds. These results reinforce the idea of PVC chlorine atom - ZnS interaction as a possible stabilization pathway, which may explain a molecular protection greater than $70 \%$ upon the addition of $\mathrm{ZnS} 0.7 \% \mathrm{wt}$.

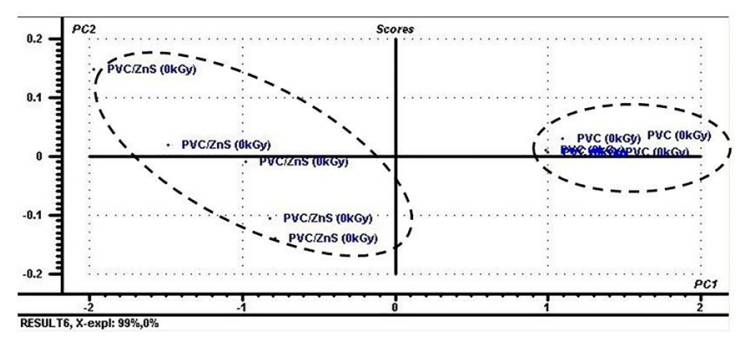

Figure 7. Score plots of $\mathrm{PC} 1 \times \mathrm{PC} 2$ of $\mathrm{PVC}$ and $\mathrm{PVC} / \mathrm{ZnS}$ films.

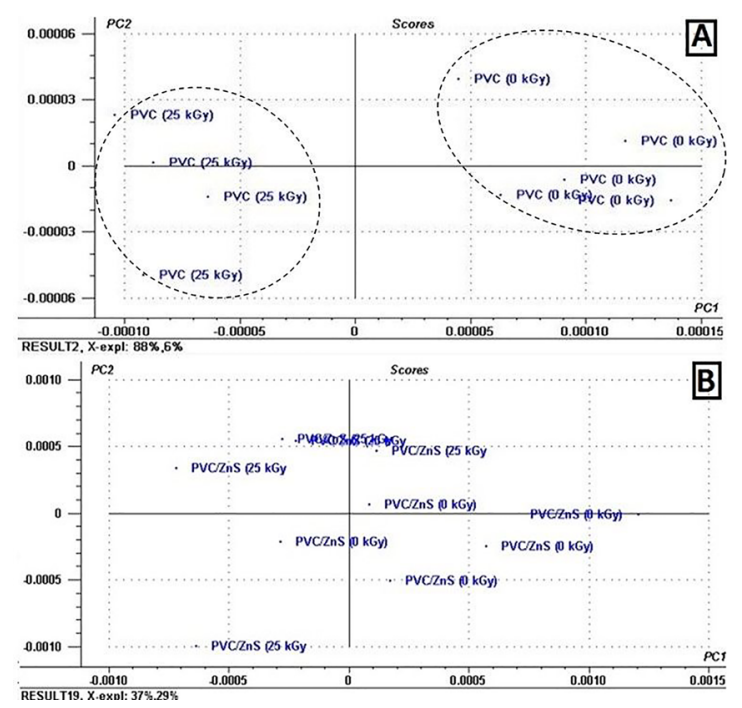

Figure 8. Score plots of PC1 x PC2 of irradiated systems for a) $\mathrm{PVC}$ and b) $\mathrm{PVC} / \mathrm{ZnS}$.

\subsection{Mechanical properties}

The influence of $\mathrm{ZnS}$ nanocrystals on PVC mechanical properties was investigated through tension tests. The results of tensile strength (TS) and Young's modulus (Ym) for PVC and $\mathrm{PVC} / \mathrm{ZnS}(0.7 \mathrm{wt} \%)$ are summarized in Table 3 for both irradiated and non-irradiated samples. The mean values of the mechanical properties were statistically compared by Student's t-test, with a significance level of $5 \%(p<0.05)$.

The tensile strength expresses the maximum strength of the material when under tension ${ }^{41}$. By the Student's t-test it was observed that $\mathrm{ZnS}$ incorporation causes a decrease around $10 \%$ in tensile strength when compared to non-irradiated samples. In relation to the Young's modulus, the values found for PVC/ZnS decreased 25\% when compared to $\mathrm{Ym}$ values of PVC. Thus, the incorporation of $\mathrm{ZnS}$ in the PVC matrix resulted in a less resistant material by decreasing of tensile strength value and a less rigid material by decreasing Young's modulus. As PVC is a rigid polymer, this change in stiffness is very positive when the films are intended for 
Table 3. Mechanical results obtained for $\mathrm{PVC}$ and $\mathrm{PVC} / \mathrm{ZnS}$.

\begin{tabular}{lccc}
\hline & Dose (kGy) & YM & TS \\
(MPa) & MPa) & $44.42 \pm 1.34^{\mathrm{a}}$ \\
\hline PVC & 0 & $2,672.38 \pm 104.81^{\mathrm{a}}$ & $33.91 \pm 2.55^{\mathrm{b}}$ \\
\hline PVC/ZnS & 25 & $1,621.80 \pm 128.73^{\mathrm{b}}$ & $37.09 \pm 2.54^{\mathrm{c}}$ \\
& 0 & $2,000.64 \pm 58.33^{\mathrm{c}}$ & $40.09 \pm 1.90^{\mathrm{c}}$ \\
\hline
\end{tabular}

Means with the same letter in the same column do not differ with $\mathrm{p}<0.05$ for the Student's t-test.

applications which require higher flexibility, such as medical use materials.

PVC shows intermolecular dipole-dipole attraction between the electron-rich chlorine atom of a PVC chain (negative pole) and electron-deficient chlorine-bonded carbon at a nearby PVC molecule (positive pole). New C-Cl $\mathrm{Zn}$ interactions formed in the presence of $\mathrm{ZnS}$, as suggested by PCA analysis (Figure 7) might weaken interchain interactions, causing increase in macromolecular mobility and decrease in the density of entanglement points ${ }^{32,38}$.

On the other hand, PVC sample irradiated at $25 \mathrm{kGy}$ exhibited lower TS and Ym values when compared to nonirradiated PVC samples (Table 3). As viscosity analysis revealed radiolysis with main chain scissions at $25 \mathrm{kGy}$ dose (Table 2), a decrease in the density of entanglements points is expected as a consequence of shorter PVC molecules after irradiation. However, no statistically significant changes were found for irradiated PVC/ZnS. These results are explained by stabilizing action of $\mathrm{ZnS}$ on PVC matrix and agree with viscosity measurements.

\section{Conclusions}

$\mathrm{ZnS}$ nanoparticles were synthesized through sonochemical method as a nanocrystalline powder. The dispersion of these nanostructures in PVC matrix at low concentration $(0.7 \mathrm{wt} \%)$ resulted in radiolytic stabilization by decreasing degradation index from 0.094 to 0.024 . PCA analysis performed in FTIR spectra of PVC films containing $\mathrm{ZnS}$ indicated $\mathrm{C}-\mathrm{Cl} \cdots \mathrm{ZnS}$ interactions. Such interactions might have contributed to improved mechanical properties of $\mathrm{PVC} / \mathrm{ZnS}$ systems. Our findings might have paved the way to a new line of affordable additive nanoparticles for radiolytic stabilization and mechanical improvement of PVC.

\section{Acknowledgments}

We would like to thank CNPq-Brazil for financial support and BRASKEM-Brazil for PVC samples.

\section{References}

1. Hanemann T, Szabó DV. Polymer-Nanoparticle Composites: from Synthesis to Modern Applications. Materials. 2010;3(6):3468-3517.
2. Li P, Chen X, Zeng JB, Gan L, Wang M. Enhancement of the interfacial interaction between poly(vinyl chloride) and zinc oxide modified reduced graphene oxide. RSC Advances. 2016;6(7):5784-5791.

3. Chen $\mathrm{CH}$, Teng CC, Yang CH. Preparation and Characterization of rigid poly (vinyl chloride)/MMT nanocomposites. Journal of Polymer Science: Part B: Polymer Physics. 2005;43(12):14651474.

4. Fang X, Zhai T, Gautam UK, Li L, Wu L, Bando Y, et al. ZnS nanostructures: From synthesis to applications. Progress in Materials Science. 2011;56(2):175-287.

5. Murugadoss G. Synthesis and photoluminescence properties of zinc sulfide nanoparticles doped with copper using effective surfactants. Particuology. 2013;11(5):566-573.

6. Kolahi S, Farjami-Shayesteh S, Azizian-Kalandaragh Y. Comparative studies on energy-dependence of reduced effective mass in quantum confined $\mathrm{ZnS}$ semiconductor nanocrystals prepared in polymer matrix. Materials Science in Semiconductor Processing. 2011;14(3-4):294-301.

7. Ogata T, Hirakawa N, Nakashima Y, Kuwahara Y, Kurihara $\mathrm{S}$. Fabrication of polymer/ZnS nanoparticle composites by matrix-mediated synthesis. Reactive \& Functional Polymers. 2014;79:59-67.

8. Osuntokun J, Ajibade PA. Structural and Thermal Studies of $\mathrm{ZnS}$ and CdS Nanoparticles in Polymer Matrices. Journal of Nanomaterials. 2016;2016:3296071.

9. Tiwari A, Dhoble SJ. Stabilization of ZnS nanoparticles by polymeric matrices: syntheses, optical properties and recent applications. RSC Advances. 2016;6(69):64400-64420.

10. Harifi T, Montazer M. A review on textile sonoprocessing: a special focus on sonosynthesis of nanomaterials on textile substrates. Ultrasonics Sonochemistry. 2015;23:1-10.

11. Suslick KS, Choe SB, Cichowlas AA, Grinstaff MW. Sonochemical synthesis of amorphous iron. Nature. 1991;353:414-416.

12. Xu H, Zeiger BW, Suslick KS. Sonochemical synthesis of nanomaterials. Chemical Society Reviews. 2013;42(7):25552567.

13. Albuquerque MCC, Garcia OP, Aquino KAS, Araujo PLB, Araujo ES. Stibnite Nanoparticles as a New Stabilizer for Poly (Methyl Methacrylate) Exposed to Gamma Irradiation. Materials Research. 2015;18(5):978-983.

14. Garcia OP, Albuquerque MCC, Aquino KAS, Araujo PLB, Araujo ES. Use of Lead (II) Sulfide Nanoparticles as Stabilizer 
for PMMA Exposed to Gamma Irradiation. Materials Research. 2015;18(2):365-372.

15. Goharshadi EK, Hadadian M, Karimi M, Azizi-Toupkanloo H. Photocatalytic degradation of reactive black 5 azo dye by zinc sulfide quantum dots prepared by a sonochemical method. Materials Science in Semiconductor Processing. 2013;16(4):1109-1116.

16. Xu JF, Ji W, Lin JY, Tang SH, Du YW. Preparation of ZnS nanoparticles by ultrasonic radiation method. Applied Physics A. 1998;66(6):639-641.

17. She YY, Yang J, Qiu K. Synthesis of ZnS nanoparticles by solid-liquid chemical reaction with $\mathrm{ZnO}$ and $\mathrm{Na} 2 \mathrm{~S}$ under ultrasonic. Transactions of Nonferrous Metals Society of China. 2010;20(Suppl 1):s211-s215.

18. Zhao Z, Geng F, Cong H, Bai J, Cheng H. A simple solution route to controlled synthesis of $\mathrm{ZnS}$ submicrospheres, nanosheets and nanorods. Nanotechnology. 2006;17(18):4731-4735.

19. Nanda J, Sapra S, Sarma DD, Chandrasekharan N, Hodes G. SizeSelected Zinc Sulfide Nanocrystallites: Synthesis, Structure, and Optical Studies. Chemistry of Materials. 2000;12(4):1018-1024.

20. Biswas S, Kar S, Chaudhuri S. Synthesis and Characterization of Zinc Sulfide Nanostructures. Synthesis and Reactivity in Inorganic, Metal-Organic, and Nano-Metal Chemistry. 2006;36(1):33-36.

21. Silva FF, Aquino KAS, Araújo ES. Effects of gamma irradiation on poly(vinyl chloride)/polystyrene blends: Investigation of radiolytic stabilization and miscibility of the mixture. Polymer Degradation and Stability. 2008;93(12):2199-2203.

22. Silva WB, Aquino KAS, Vasconcelos HM, Araújo ES. Influence of copper chloride and potassium iodide mixture in poly(vinyl chloride) exposed to gamma irradiation. Polymer Degradation and Stability. 2013;98(1):241-245.

23. Guillet J. Polymer Photophysics and Photochemistry. New York: Cambridge University Press; 1985.

24. Brandrup J, Immergut EH, eds. Polymer Handbook. New York: John Wiley Sons; 1989.

25. Charlesby A. Atomic Radiation and Polymers. New York: Pergamon Press; 1960.

26. Solomo OF, Ciută IZ. Détermination de la viscosité intrinsèque de solutions de polymères par une simple détermination de la viscosité. Journal of Applied Polymer Science. 1962,6(24):683-686.

27. Mathiesen L, Malterud KE, Sund RB. Hydrogen Bond Formation as Basis for Radical Scavenging Activity: A Structure-Activity Study of C-Methylated Dihydrochalcones from Myrica Gale and Structurally Related Acetophenones. Free Radical Biology \& Medicine. 1997;22(1-2):307-311.
28. ASTM International. ASTM D882-12 - Standard Test Method for Tensile Properties of Thin Plastic Sheeting. West Conshohocken: ASTM International; 2012.

29. Nanev C, Iwanov D. Direct synthesis of epitaxial zinc sulphide layers on zinc single-crystal substrates. Thin Solid Films. 1976;35(2):155-163.

30. Hotze EM, Phenrat T, Lowry GV. Nanoparticle Aggregation: Challenges to Understanding Transport and Reactivity in the Environment. Journal of Environmental Quality. 2010;39(6):1909-1924.

31. Zemb T, Kunz W. Weak aggregation: State of the art, expectations and open questions. Current Opinion in Colloid \& Interface Science. 2016;22:113-119.

32. Vinhas GM, Souto-Maior RM, Almeida YMB, Neto BB. Radiolytic degradation of poly(vinyl chloride) systems. Polymer Degradation and Stability. 2004;86(3):431-436.

33. Vinhas GM, Souto Maior RM, Almeida YMB. Radiolytic degradation and stabilization of poly(vinyl chloride). Polymer Degradation and Stability. 2004;83(3):429-433.

34. Mendizabal E, Cruz L, Jasso CF, Burillo T, Davin VT. Radiation crosslinking of highly plasticized PVC. Radiation Physics and Chemistry. 1996;47(2):305-309.

35. Lee EH, Rao GR, Mansur LK. LET effects on cross-linking and scission mechanism of PVC during irradiation. Radiation Physics and Chemistry. 1999;55(3):293-305.

36. Von Cottrel TL. The Strengths of Chemical Bonds. London: Butterworths; 1954.

37. Lendvay G, Bérces T. Radical Scavenging and excited state quenching efficiency of additives in the photochemistry of acetone. Journal of Photochemistry and Photobiology, A: Chemistry. 1987; 40: 31-45.

38. Ramesh S, Leen KH, Kumutha K, Arof AK. FTIR studies of PVC/PMMA blend based polymer electrolytes. Spectrochimica Acta Part A: Molecular and Biomolecular Spectroscopy. 2007;66(4-5):1237-1242.

39. Rajendran S, Uma T. Effect of $\mathrm{ZrO}_{2}$ on conductivity of PVC$\mathrm{LiBF}_{4}$-DBP polymer electrolytes. Materials Letters. 2000;44(34):208-214

40. Colombani J, Labed V, Joussot-Dubien C, Périchaud A, Raffi J, Kister J, et al. High doses gamma radiolysis of PVC: Mechanisms of degradation. Nuclear Instruments and Methods in Physics Research Section B: Beam Interactions with Materials and Atoms. 2007;265:238-244.

41. Lipatov YS. Polymer Reinforcement. Toronto: ChemTec Publishing; 1995. 